\title{
EL CONGRESO
}

MEXICANO Y

EL TRATADO DE

GUADALUPE HIDALGO

Reynaldo Sordo*

$\mathrm{E}_{12} 2$ de febrero de 1998 se cumplieron 150 años de la firma del Tratado de Guadalupe Hidalgo, tratado que dio término a la guerra de México con los Estados Unidos, definió, prácticamente, la frontera entre los dos países y regularizó una difícil relación entre las dos naciones, marcada por una creciente asimetría hasta nuestros días. El 30 de mayo de 1998 se cumplen 150 años del canje de las ratificaciones del mismo tratado entre los dos gobiernos. Lo que normalmente se ignora es que el Senado norteamericano modificó el tratado original y el Congreso mexicano lo ratificó, a pesar de que las modificaciones, alteraban, si no esencialmente, sí en puntos importantes, los acuerdos de Guadalupe Hidalgo. Este ensayo pretende explicar por qué el Congreso pudo aprobar el tratado, con las modificaciones del Senado norteamericano, a pesar del clima de faccionalismo que se había generado durante el año de 1848 .

La derrota militar tuvo desde el principio un sinnúmero de explicaciones. En todas ellas, los autores coincidían en que el fracaso de México era consecuencia lógica de 25 años de anarquía política, falta de cohesión en las clases dirigentes y faccionalismo.

* Departamento Académico de Estudios Generales, ITAM. 
El desconcierto político llegó a su clímax en los años cuarenta. Entre finales de 1845 y mediados de 1848, período aproximadamente de dos años y medio, gobernarían y se disputarían el poder los cinco principales grupos políticos de esa década: centralistas, monarquistas, santanistas, liberales puros y liberales moderados. "En el momento clave del enfrentamiento con los Estados Unidos, el país pasaría del centralismo de las Bases Orgánicas, a un régimen militar que coqueteaba con la monarquía, a una república federal, en la que finalmente puros y moderados hundirían al país en un desconcierto sin precedente, precisamente cuando se necesitaba unidad y un centro de acción que dirigiera la guerra." A esto habría que agregar, la presencia siempre inquietante del general Antonio López de Santa Anna y de sus seguidores, que siempre polarizaba las opiniones en favor o en contra.

En un período tan corto y crítico estuvieron vigentes tres constituciones, hubo 9 gobiernos, cuatro congresos distintos, dos congresos constituyentes y cuatro procesos electorales de carácter nacional, efectuados bajo disposiciones legales diferentes. No es de extrañar que el faccionalismo estuviera al rojo vivo, entre 1845 y 1848 , pues todos estos cambios en el proceso político, tenían su origen en la lucha por el poder entre los grupos antes mencionados. De todos los cambios efectuados en el período, uno de los más decisivos fue el de agosto de 1846 , cuando los federalistas puros tomaron el poder con ayuda del general Santa Anna.

\section{Faccionalismo y guerra}

El Plan de la Ciudadela proclamado por el general Mariano Salas, el 4 de agosto de 1846, en la ciudad de México, convocaba a un congreso popular para constituir a la nación y resolver todo lo relativo a la

${ }^{1}$ Reynaldo Sordo y Josefina Vázquez, En Defensa de la Patria, 18471997, 1997, México, Comisión organizadora de los Homenajes del CL Aniversario de los Niños Héroes-Secretaría de Gobernación-Archivo General de la Nación, p. 23. 
guerra con los Estados Unidos, e invitaba al general Santa Anna a ser jefe de las fuerzas comprometidas en la revolución. ${ }^{2}$

Este movimiento derrocó al gobierno del general Mariano Paredes y Arrillaga a quien se acusó de proteger la monarquía y engañar a la nación al reunir un Congreso anti-popular. Los principales líderes de la revolución eran federalistas puros, quienes habían pactado con Santa Anna y sectores importantes del ejército para derrocar a Paredes.

Mariano Salas fue nombrado jefe del ejecutivo, provisionalmente, y su primer acto de gobierno fue hacer la convocatoria para la elección de diputados al Congreso, que sería constituyente, formado por una sola cámara, y tendría que reunirse en el plazo de cuatro meses. También el general Salas restableció la Constitución Federal de 1824 y amplió las atribuciones del futuro Congreso, por decretos del 22 de agosto de $1846 .^{3}$

Los federalistas habían logrado tomar el poder, restablecer la Constitución de 1824 , ver a los centralistas derrotados y a los monarquistas totalmente desprestigiados. Todo presagiaba un futuro prometedor para la marcha pública y para hacer frente a la invasión estadounidense.

Sin embargo, los federalistas estaban divididos en puros y moderados, dos facciones antagónicas e irreconciliables. Desde las elecciones se presentó la lucha de las dos facciones, y cuando se reunió el Congreso, el 6 de diciembre de 1846, estaba dividido en dos partes equivalentes de diputados puros y moderados. En ambas facciones encontramos personas notables: entre los puros a Manuel Crescencio Rejón, Vicente Romero, Francisco Suárez Iriarte y Benito Juárez; en la facción moderada a Mariano Otero, Mariano Riva Palacio, José Joaquín de Herrera, José María Lafragua y José María Lacunza.

2 "Plan de la Ciudadela" (4 de agosto de 1846), en Josefina Vázquez (coord.), Planes en la Nación Mexicana, 1987, México, Senado de la República-El Colegio de México, Libro cuatro, p. 321-2.

${ }^{3}$ Manuel Dublán y José María Lozano, Legislación mexicana o colección completa de las disposiciones legislativas desde la independencia de la República, edición oficial, México, Imprenta del Comercio a cargo de Dublán y Lozano hijos, vol. v, p. 156. 
REYNALDO SORDO

El Congreso constituyente tuvo dos asuntos principales que atender: redactar una Constitución y enfrentar los problemas derivados de la guerra con los Estados Unidos. En éstos, como en todos los asuntos tratados por el Congreso, no hubo un centro de unidad, como lo requería el momento, sino todo lo contrario, el Congreso fue un foco de división, antagonismo y disolución de la moral y el espíritu público.

El Congreso nombró al general Santa Anna y a Valentín Gómez Farías, líder de la facción de los puros, presidente y vicepresidente interinos respectivamente. Gómez Farías se hizo cargo del Poder Ejecutivo y Santa Anna dedicó su actividad a reunir un ejército en la ciudad de San Luis Potosi. ${ }^{4}$

El Congreso tuvo el primer gran debate al autorizar al gobierno para que se proporcionara hasta 15 millones de pesos, hipotecando o vendiendo en subasta pública los bienes de la Iglesia. La ley fue aprobada por 44 votos contra 41, el 11 de enero de 1847. Las discusiones duraron tres días, en los que el Congreso estuvo en sesión permanente. Los moderados lograron muchas restricciones a la ley, que la hacían muy difícil de aplicar. La oposición de la Iglesia y de los moderados fue muy fuerte y el gobierno no logró el objetivo de hacerse de recur-

62 sos económicos para la guerra. Santa Anna movió al ejército con los mínimos recursos que él consiguió. El Congreso intentó otra acción desesperada con la ley del 4 de febrero, en la que se facultaba extraordinariamente al gobierno para proporcionarse hasta 5 millones de pesos, para atender a la defensa del territorio. ${ }^{5}$

Los moderados sintieron que no podían derrotar a los puros en el Congreso y, entonces, promovieron una revolución con algunos cuerpos de la guardia nacional, dirigidos por el general Matías de la Peña y Barragán, el 27 de febrero de 1847 , pocos días después de la batalla

${ }^{4}$ Soberano Congreso Constituyente, sesión del 23 de diciembre de 1836, Diario del Gobierno de la República Mexicana (DGRM), 1 de enero de 1847.

${ }^{5}$ DGRM, 26 de enero de 1847, Archivo General de la Nación, Fondo Gobernación, sin sec., vol. 326, exp. 11. 
de la Angostura. Estos cuerpos estaban formados por los hijos de las mejores familias de la capital, a quienes el pueblo llamó polkos. ${ }^{6}$

Santa Anna regresó a poner fin a la revolución de los polkos y tomó partido por los moderados. El Congreso facultó al gobierno para conseguir 20 millones de pesos y se derogaron las leyes del $11 \mathrm{de}$ enero y 4 de febrero. El Congreso, en medio de otro acalorado debate, declaró insubsistente la vicepresidencia y nombró presidente sustituto al general Pedro María Anaya, candidato de los moderados. ${ }^{7}$

Santa Anna salió a pelear contra el ejército estadounidense, que había desembarcado en Veracruz y avanzaba hacia la ciudad de México. E1 18 de abril, sufrió una nueva derrota en Cerro Gordo, Veracruz. Inmediatamente, el Congreso se reunió a discutir una ley que se aprobó el 20 de abril. Por ella se facultaba al gobierno a tomar medidas necesarias para llevar la guerra adelante y no se autorizaba al ejecutivo a establecer la paz con los Estados Unidos, conluir negociación con las potencias extranjeras, ni enajenar el territorio de la república. Las votaciones a esta ley fueron casi por unanimidad, y fue éste el único asunto importante en que coincidieron puros y moderados. Seguramente, ambos tenían miedo de que Santa Anna hiciera algún trato con los norteamericanos, a espaldas del Congreso. El resultado fue que el Poder Legislativo, ni dio recursos al Ejecutivo para hacer la guerra, ni le permitió hacer la paz a través de negociaciones. ${ }^{8}$

El Congreso, en los meses más turbulentos de abril y mayo, abordó el tema de la Constitución. Con tantos problemas surgidos del faccionalismo y de la guerra, los diputados llegaron a la conclusión de sólo reformar la Constitución de 1824, en lugar de elaborar una nueva carta magna. Mariano Otero presentó al Congreso un conjunto de

${ }^{6} \mathrm{AGN}$. FG, sin sec., vol. 337, exp. 7. El nombre deriva de que la polka era el baile de moda entre la aristocracia de la capital.

${ }^{7}$ Soberano Congreso Constituyente, sesión extraordinaria de la noche del 30 de marzo; sesión permanente del 31 de marzo hasta el 1 de abril de $1847, D G R M, 9$ y 12 de abril de 1847.

${ }^{8}$ Dublán y Lozano, op. cit., v, p. 208. 


\section{REYNALDO SORDO}

reformas agrupadas en el documento llamado Acta de Reformas. Este documento sirvió de base para la discusión y fue aprobado, después de un penoso debate, que no alteró su esencia, el 18 de mayo de $1847 .^{9}$

A partir de este momento, el Congreso casi no se reunió por falta de número y sólo pasó la ley sobre elección de poderes, que el gobierno publicó el 3 de junio. A estas alturas, el Congreso estaba completamente desprestigiado. Como era un Congreso constituyente y la Constitución ya se había dado, su única razón de existir podía ser la de enfrentar la guerra. Hasta la ocupación de la ciudad de México por las tropas norteamericanas, en septiembre de 1847, el Congreso no se reunió y el Ejecutivo no pudo hacer la paz.

\section{Paz o guerra}

Después de la caída de México, los diputados comenzaron a viajar a la ciudad de Querétaro, mientras en Toluca, Manuel de la Peña y Peña establecía un gobierno provisional, como magistrado más antiguo de la Suprema Corte de Justicia. ${ }^{10} \mathrm{El}$ presidente provisional y su 64 ministro universal, Luis de la Rosa, llegaron a Querétaro el 12 de octubre, cuando aún no se reunía un número suficiente de diputados para tener sesiones. Poco a poco la "ciudad santa" de tierra adentro se fue convirtiendo en la "nueva Babilonia" del país. Manuel González Cosío, gobernador de Zacatecas le decía al líder de los puros, a me-

${ }^{9}$ Reynaldo Sordo, "E1 Congreso y la Guerra con Estados Unidos de América, 1846-1848", en Josefina Vázquez coord., México al Tiempo de su Guerra con Estados Unidos (1846-1848), 1997, México, FCE-El Colegio de México-SRE, p. 85-8.

${ }^{10}$ Circular del Excmo. Sr. D. Manuel de la Peña y Peña, como Presidente provisional de la República, a los Excmos. Sres. Gobernadores de los Estados, en Poder Ejecutivo, Colección de los documentos más importantes relativos a la instalación y reconocimiento del Gobierno Provisional del Excmo. Sr. presidente de la Suprema Corte de Justicia D. Manuel de la Peña y Peña, 1847, México, Ignacio Cumplido, p. 12-5. 
diados de octubre, quien se encontraba en Lagos: "¿qué hace U. en Lagos? El campo de batalla está en Querétaro". "El faccionalismo no había disminuido a pesar de la derrota y la caída de la ciudad de México.

El gobierno de Peña y Peña, dominado por los moderados, estaba decidido por la negociación y la paz. Los federalistas puros querían continuar la guerra hasta perecer y sólo aceptaban la negociación, si los estadounidenses desocuparan el país y dejaran de bloquear las costas mexicanas. Los moderados pensaban que la negociación llevaría a la pérdida de un territorio importante, pero con este sacrificio lograrían salvar la nacionalidad. Los puros, por el contrario, pensaban que cualquier cesión territorial era inadmisible y ponía en peligro la existencia de México. ${ }^{12}$

El gobierno de Peña y Peña, a pesar de ser precario, resolvió varios problemas cruciales entre octubre y diciembre de 1847: recibir apoyo de la mayoría de los estados no ocupados por el ejército estadounidense; comenzar la negociación formal con el enviado del presidente James Polk, Nicolás Trist; eliminar al general Santa Anna, quien pretendía continuar la guerra y regresar al poder; efectuar elecciones para formar el nuevo Congreso que comenzaría a funcionar el 1 de enero, de acuerdo a la ley del 3 de junio de 1847 y el Acta de Reformas; neutralizar la oposición de los federalistas puros que querían continuar la guerra; hacer una reunión con los gobernadores de los estados para que apoyaran la política del gobierno nacional; reunir al Congreso constituyente para legitimar sus acciones y elegir presidente interino de la república. Asombra ver cómo, en situaciones tan críticas, Peña y Peña tuvo éxito en todos sus objetivos políticos. ${ }^{13}$

${ }^{11}$ Manuel González Cosio a Valentín Gómez Farías, Zacatecas, 15 de octubre de 1847, Archivo Valentín Gómez Farías (AVGF), 2833.

${ }^{12}$ Reynaldo Sordo, Paz o Guerra. Junta de Gobernadores en Querétaro, noviembre de 1847, ponencia presentada en el Archivo General de la Nación, el 13 de noviembre de 1997 (en prensa).

${ }^{13}$ Ibid. 
REYNALDO SORDO

E1 2 de noviembre se reuniría, por fin, el Congreso constituyente. Poco hicieron los diputados por el país: eligieron presidente interino a Pedro María Anaya y tuvieron agrias discusiones por continuar la guerra o hacer la paz. El Congreso estuvo en gran fermento durante el mes de noviembre. Los desatinos llegaron a niveles increíbles. Mariano Otero propuso una ley que impidiera al gobierno enajenar territorio alguno, a excepción de Texas. Un buen número de diputados apoyaban esta propuesta, pero, para asombro nuestro, el partido puro rechazó la idea de Otero, porque pensaba que tampoco Texas se debía perder. Con esto, el partido puro perdió la posibilidad de ponerle límites a la negociación del gobierno moderado de Peña y Peña. El 19 de ese mes, Pedro Zubieta propuso la disolución del pacto federativo de 1824; que cada estado reasumiera su soberanía y se organizara de acuerdo a sus intereses y que después se volvieran a confederar para continuar la guerra. El Congreso constituyente dejó de reunirse en los primeros días de diciembre, por falta de número. ${ }^{14}$

\section{El Congreso y el Tratado de paz}

E1 decreto de elección de presidente provisional del 10 de noviembre de 1847 disponía que el 8 de enero de 1848 cesara en sus funciones y el Congreso hiciera la elección correspondiente. Al no estar reunido el Congreso, el presidente de la Suprema Corte de Justicia se encargaría del Poder Ejecutivo provisionalmente. En tal virtud, Manuel de la Peña y Peña volvió a encargarse de la presidencia. Pedro María Anaya y Manuel de la Peña y Peña pertenecían al partido moderado, por lo que la continuidad en las políticas no se vio afectada por el nuevo cambio de gobierno. ${ }^{15}$

${ }^{14}$ Congreso General, sesiones de los días 4, 6, 8 y 19 de noviembre de 1847, El Correo Nacional (CN), 30 de noviembre, 2 y 23 de diciembre de 1847 .

15 "El presidente provisional a sus conciudadanos", 8 de enero de 1848 , $C N, 11$ de enero de 1848 . 
La situación de 1848 no sería más fácil que la de finales de 1847. El segundo gobierno de Peña y Peña tuvo que sortear numerosos escollos en el camino: realizar una buena negociación con los estadounidenses, neutralizar los intentos federalistas por desconocer al gobierno de Querétaro, funcionar con gran escasez de recursos, enfrentar la oposición en contra del tratado y evitar la disolución del pacto federal, como pequeños grupos extremistas lo proponían.

Para dar fin a la guerra, los gobiernos de Manuel de la Peña y Peña y Pedro María Anaya negociaron un tratado de paz con los Estados Unidos, firmado el 2 de febrero de ese año, en la villa de Guadalupe Hidalgo. El tratado contenía una cesión de territorio considerable, mas dadas las circunstancias y las ambiciones territoriales del presidente Polk, puede considerarse una buena negociación. Pero sobre todo, los negociadores mexicanos lograron proteger los derechos de los habitantes del territorio que México cedía a los Estados Unidos por el tratado. $^{16}$

El tratado fue enviado a Washington. El presidente Polk no lo vio con buenos ojos. Sin embargo, por las circunstancias políticas que vivía aquel país, lo aprobó y remitió al Senado con algunas recomendaciones y explicando las irregularidades habidas en la negociación, dado que Trist negoció cuando ya se le habían retirado sus poderes. El Senado discutió el tratado ampliamente e hizo siete modificaciones que perjudicaban a México. El 10 de marzo, el Senado lo aprobó por 38 votos contra $14 .^{17}$

En México, la ratificación del tratado, de acuerdo con la Constitución de 1824 y el Acta de Reformas de 1847, recaía en el Congreso, por eso era vital su reunión en Querétaro, a partir de enero de 1848. Este nuevo Congreso sustituiría al constituyente, que por su carácter la ley del 3 de junio de 1847 había dispuesto que desapareciera en

${ }^{16}$ Para un estudio pormenorizado del contenido del tratado ver el excelente estudio: Ana Rosa Suárez, De Maine a México. La misión diplomática de Nathan Clifford (1848-1849), 1994, México, SRE-Instituto Mora.

${ }^{17}$ Ibid., p. 67-88. 
REYNALDO SORDO

diciembre de ese año. Este nuevo Congreso sería ya un congreso ordinario y por lo tanto estaría dividido en dos cámaras, de diputados y senadores. ${ }^{18}$ "Formar el Congreso, más que en ninguna otra época, era una tarea difícil, con muchas pequeñas complicaciones. Las elecciones se habían realizado en plena guerra, estando ocupados varios estados por los norteamericanos y con base en una legislación muy compleja que encerraría serias dudas sobre la legitimidad de las mismas." 19

Las elecciones se efectuaron en 15 estados entre agosto y octubre de 1847. El gobierno de Peña y Peña negoció un armisticio con el ejército invasor en los primeros meses de 1848. El 9 de marzo entró en vigor el armisticio con lo cual cesaban las hostilidades entre los dos países. El armisticio facilitó que hubiera elecciones en algunos lugares donde no se habían efectuado por la ocupación estadounidense.

Comparando la correspondencia de dos de los principales líderes, Valentín Gómez Farías del partido puro, y Mariano Riva Palacio del moderado, uno puede apreciar fácilmente que los moderados desplegaron una gran actividad para influir en las elecciones y los miembros del partido puro se perdieron en empresas improductivas y descabelladas: formación de coaliciones, intentos de levantamientos, acopio y traslado de armas, etc. El resultado final fue que el partido moderado triunfó ampliamente en los comicios y por lo tanto contó con el número suficiente de diputados y senadores para controlar el Congreso y aprobar el tratado de paz. ${ }^{20}$

El nuevo Congreso tardó mucho tiempo en reunirse. Los primeros diputados y senadores comenzaron a llegar en el mes de enero, pero el Congreso no se instaló hasta el 7 de mayo de 1848. Los moderados dominaban las dos cámaras: la de diputados con $60 \%$ y la de senadores con $90 \%$. Entre los moderados se encontraban Mariano Riva Palacio, Manuel Payno y Manuel Gómez Pedraza. Los puros tenían represen-

${ }^{18}$ Ley del 3 de junio de 1847, Dublán y Lozano, op. cit., v, p. 281-3.

${ }^{19}$ Sordo, "El Congreso...", op. cit., p. 95.

${ }^{20}$ Ver AVGF, 2814, 2832, 2837, 2858; AMRP, 2412, 2575, 2599, 2557. 
tantes importantes como Vicente Romero, Manuel Doblado y Ponciano Arriaga. $^{21}$

Los congresistas puros, principalmente en la cámara de diputados, desde la instalación del Congreso hicieron esfuerzos por evitar que se aprobara el tratado: presentaron pruebas de irregularidades en las elecciones, pidieron reprobar la negociación, propusieron derogar las facultades extraordinarias del Ejecutivo y, finalmente, trataron de convencer al Congreso de que se comenzara a negociar de nuevo con los Estados Unidos. Todas las iniciativas de los diputados puros fueron desechadas por el pleno del Congreso. Los puros no pudieron hacer nada al no contar con una mayoría de votos en ambas cámaras. ${ }^{22}$

Una vez instalado el Congreso, Francisco Elorriaga y Manuel Gómez Pedraza fueron elegidos presidentes de la cámara de diputados y senadores, respectivamente. Los dos pertenecían al partido moderado. El día 14 de mayo, el Congreso eligió presidente interino a Manuel de la Peña y Peña. "Los moderados tenían el control del proceso para aprobar el tratado: mayoría en las dos cámaras, moderados en la presidencia de ambas cámaras, confirmación de Peña y Peña en la dirección del gobierno y un estrategia para que el asunto avanzara sin dilaciones.,"23

El gobierno presentó al Congreso tres documentos: del presidente Peña y Peña, el ministro Luis de la Rosa y los comisionados Bernardo Couto, Luis G. Cuevas y Miguel Atristáin. Razonando de lo general a lo particular, el primero argumentaba que el tratado era la única forma de salvar la nacionalidad, el segundo decía que los publicistas afirmaban que se podía ceder territorio ante un mal mayor, y el tercero concluía expresando que el tratado era más un tratado de recuperación que de cesión, ya que México recuperaba vastos territorios ocupados por el ejército invasor. ${ }^{24}$

${ }^{21}$ El Correo Nacional, 4 y 18 de mayo de 1848.

${ }^{22}$ Cámara de diputados, segunda junta preparatoria, 1 de mayo de 1848 y sesiones de los días 11 y 16 de mayo de $1848, C N, 8$ y 20 de mayo de 1848 . ${ }^{23}$ Sordo, op. cit., p. 99-100.

24 "Mensaje del Excmo. presidente provisional de la República D. Manuel de la Peña y Peña leído en la apertura de sesiones del Congreso de 1848", 
REYNALDO SORDO

El gobierno presentó, en conjunto, una argumentación sólida al Congreso para que procediera a discutir el tratado. Parte muy importante de la argumentación se fundaba en la situación interna del país: falta absoluta de recursos para continuar la guerra, disolución del ejército después de la caída de la ciudad de México, actitud hostil de los estados y mala comprensión del federalismo, faccionalismo exacerbado en los grupos políticos, creciente desarrollo de la guerra de castas en varios lugares del país y conatos de levantamientos contra el gobierno de Querétaro. Continuar la guerra en estas circunstancias, argumentaba el gobierno, sólo podía causar más males a la nación y una mayor pérdida de territorio. ${ }^{25}$

El tratado con la documentación respectiva pasaría a la comisión de relaciones de la cámara de diputados, dominada por moderados. La comisión presentaría a la cámara el dictamen correspondiente, que concluía con la proposición: "Se aprueba el Tratado celebrado con los Estados Unidos del Norte, en 2 de Febrero de este año, con las modificaciones hechas por el senado y gobierno de los mismos Estados Unidos." 26

El debate comenzaría el día 13 y terminaría el 18, día de la votación. Los testigos de la época, como Guillermo Prieto y José Ramón Malo, dejaron consignado en sus Memorias y en su Diario, respectivamente, que la discusión fue lúcida, interesante y enriquecedora. Prieto nos dejó un relato vívido de los debates, pero sobre todo del discurso del diputado José María Cuevas, quien estando enfermo se presentó en camilla al Congreso para hablar en favor de la guerra:

$C N, 8$ de mayo de 1848; "Exposición con que el ministro de Relaciones presenta al Congreso nacional el tratado de paz celebrado entre México y Estados Unidos de América", CN, Alcance al número 101, 10 de mayo de 1848; Exposición dirigida al Supremo Gobierno por los Comisionados que formaron el Tratado de Paz con los Estados Unidos, 1848, Querétaro, Imprenta de J. M. de Lara.

\section{${ }^{25} \mathrm{Ibid}$.}

26 "Dictamen de la comisión de relaciones", 13 de mayo de 1848, CN, 22 de mayo de 1848 . 
En medio de un silencio sepulcral, comenzó su discurso el señor Cuevas, y fue robusteciéndose, animando, hasta estallar en desbordamientos de ideas, en tempestades magníficas de conceptos sublimes, en inspiradas, en increíbles revelaciones de patriotismo.

Aquella especie de fantasma tenía entre sus labios lo subyugador y lo sublime...

Los diputados pálidos, con los ojos brillando en lágrimas, los labios entreabiertos ansiosos, los obedecian una evocación mágica. Concluyó de hablar el orador y cayó como exánime sobre la camilla...entonces, como si se tratara de un padre por el amor y de un niño o un ser de cristal, se le rodeó, se le prodigaron cuidados al hombre que se había hecho adorable.

Los diputados se disputaron el honor de llevarlo a su casa, en hombros y sin saber cómo se armó procesión de cirios y hachones que acompañó al orador hasta su casa. ${ }^{27}$

Las efusiones patrióticas producidas por el discurso de Cuevas no fueron suficientes para reprobar el tratado. El día 18 se votó en lo general y se aprobó por 48 votos contra $37 .^{28}$ Procedía entonces la discusión en lo particular de artículo por artículo, según práctica inveterada de los congresos mexicanos. Sin embargo, los moderados no tenían tiempo para discutir artículo por artículo, ni querían que el Congreso modificara una sola coma de lo aprobado por los estadounidenses. Los moderados sorprendieron a los puros. Para estirar la ley, todas las facciones tenían argumentos válidos. El dictamen concluía con un solo artículo: aprobar el tratado. Por lo tanto, sólo se podía discutir en lo general o en lo particular la aprobación o reprobación total del tratado. Malo consigna en su Diario lo siguiente: "El

27 Guillermo Prieto, Memorias de mis tiempos, 1985, México, Porrúa, Sepan Cuantos $n^{\circ} 481$, p. 295.

28 José Ramón Malo, Diario de Sucesos Notables (1832-1853), 1948, México, Patria, p. 331-2. 
REYNALDO SORDO

señor Arriaga pidió que se discutiera artículo por artículo, el tratado. El señor Presidente dijo que lo que se ponía a discusión, en lo particular, era la proposición de la Comisión que era una sola, y sobre esto hubo un debate acalorado entre los señores Navarro y Solana." 29 E1 19 de mayo, la cámara votó en lo particular y aprobó el tratado por 51 votos contra $35 .^{30}$

El día de la aprobación del tratado en lo particular, el líder de los federalistas puros, Valentín Gómez Farías, escribía a sus hijos con gran frustración e impotencia: "Ayer se ha aprobado el ignominioso tratado de paz por cuarenta y ocho votos contra treinta y seis y debiendo pasar de la discusión en lo general a la de cada uno de los artículos, no se hizo así, porque se aprobó contra toda regla que no se debía descender a ésta. El reglamento y la práctica se han hollado escandalosamente. En los mismos Estados Unidos se han discutido los artículos en lo particular, pero no hay leyes ni ejemplos que valgan, nuestros diputados han tomado con obstinación el camino de la perdición, y es trabajo en vano querer separarlos de él. En el Senado se aprobará el dicho tratado de la misma manera y con más celeridad y así es que la obra de perfidia quedará consumada." 31

72 Gómez Farías tenía sobrada razón. El tratado pasó al senado el día 20 , y con gran celeridad fue aprobado por 33 votos contra 4 . En la cámara alta, el gobierno contaba con una amplia mayoría en favor de la paz. La actitud de los moderados fue pragmática: el 2 de junio se vencía el tiempo para el canje de ratificaciones, y discutir artículo por artículo llevaría mucho más tiempo del que disponían y la mínima alteración hubiera sido inaceptable para Estados Unidos.

El día 26, el ministro de Relaciones hizo un protocolo con los comisionados norteamericanos, para definir la interpretación que debería darse a las modificaciones introducidas en el tratado por el Senado de

${ }^{29}$ Ibid., p. 332.

${ }^{30}$ Ibid.

${ }^{31}$ Valentín Gómez Farías a sus hijos Fermín, Casimiro y Benito, Querétaro, 19 de mayo de 1848, AVGF, 2980. 
aquel país. Al canjearse las ratificaciones en Querétaro, el 30 de mayo, terminaba el ciclo de la guerra. México había perdido Texas, Nuevo México y la Alta California, la mitad de su territorio aproximadamente, pero había logrado superar la crisis más fuerte de su historia y salvar la nacionalidad. Los moderados, contra viento y marea, apegándose a la ley unas veces, y pasando por encima de ella en otras ocasiones, lograron lo que parecía imposible al caer la ciudad de México en septiembre de 1847: conservar la independencia absoluta de la nación.

Sin embargo, una pregunta inquietante surge de todo este proceso: ¿por qué los federalistas puros y moderados fueron incapaces de llegar a acuerdos políticos, frente a un enemigo temible como lo era el invasor norteamericano? Intentaré dar una explicación.

E1 restablecimiento del federalismo, en agosto de 1846, además de los trastornos propios del cambio en el sistema de gobierno y su funcionamiento, reavivó el conflicto faccional dentro del partido liberal. El antagonismo entre puros y moderados tenía antecedentes en los años treinta. El conflicto había sido no sólo de ideas, sino de personalidades: entre Valentín Gómez Farías y Manuel Gómez Pedraza. El debate continuaría en el constituyente de 1842. En 1845, los moderados gobernarían con José Joaquín de Herrera y los puros estarían en la oposición. Durante 1845, las dos fuerzas radicalizarían sus posiciones. Las elecciones de finales de 1845, enfrentaría violentamente a puros y moderados. Los puros ganarían las elecciones, pero no llegarían al poder por el levantamiento de Mariano Paredes y Arrillaga. El enfrentamiento entre puros y moderados, entre 1846 y 1848, sería un capítulo más de esta batalla de personas, fuertemente ideologizadas y radicalizadas en sus puntos de vista.

El diputado José Agustín Escudero, estando en la "nueva Babilonia de tierra adentro", describiría con precisión esta situación, en noviembre de 1847: “...mas en el mes de noviembre se vieron aparecer multitud de personas que, aunque extraños a la administración pública, son bien notables por sus categorías sociales, en el ejército, en el comercio y aun en la influencia de los partidos que por desgracia han devorado a la nación en todos tiempos, y Querétaro se convirtió en un teatro de 
aspiraciones, esperanzas y cálculos de toda especie, que ofuscando el buen sentido y las más sanas ideas de los hombres sencillos y bien intencionados, que no han podido tener parte en las convenciones privadas de los jefes de la política, ninguna otra cosa se ha dejado comprender, sino la existencia y mayor encono de las facciones a las que pertenecen, y que recíprocamente se temen, se cautelan, se improperan y se atacan, atribuyéndose así mismos las mejores miras, y haciendo sospechar absolutamente de las que le son contrarias o diversas a su círculo". 32

Mariano Otero, prominente moderado escribía desde Toluca a Mariano Riva Palacio, en septiembre de 1847: "En los Estados resaltan las rivalidades de los partidos, de manera que por acá los puros son más descarados y los moderados más egoístas que por allá."33

En conclusión, el restablecimiento de la Constitución de 1824 no solucionó el problema fundamental de unir a las élites para hacer frente a la guerra. Por el contrario, reavivó la lucha faccional dentro del partido federalista. Las élites liberales fueron incapaces de dialogar y llegar a acuerdos mínimos. Los puros y moderados ejercieron el poder entre 1846 y 1848 con las condiciones menos favorables y con-

74 trarias a lo que requería el país en ese momento: intolerancia, personalismo, legalismo desorganizador, dogmatismo ideológico y creciente radicalismo.

${ }^{32}$ José Agustín Escudero, Memorias del diputado por el Estado de Chihuahua, con documentos justificativos, que pueden servir para la historia del Congreso Constitucional mexicano del año de 1847, 1848, México, Tipografía de R. Rafael.

${ }^{33}$ Mariano Otero a Mariano Riva Palacio, Toluca, 21 de septiembre de 1847, AMRP, 2412. 


\title{
Fuentes y bibliografía
}

\author{
Archivos
}

AGN.FG, Archivo General de la Nación, Fondo Gobernación.

AMRP, Archivo de Mariano Riva Palacio, Benson Latin American Collection, Universidad de Texas.

AVGF, Archivo de Valentín Gómez Farías, Benson Latin American Collection, Universidad de Texas.

\section{Publicaciones periódicas}

CN, El Correo Nacional, Querétaro, 1847-1848.

DGRM, Diario del Gobierno de la República Mexicana, 1846-1848, México.

\section{Bibliografia general}

Dublán, Manuel y Lozano, José María, Legislación mexicana o colección completa de las disposiciones legislativas desde la independencia de la República, edición oficial, 1876, México, Imprenta del Comercio a cargo de Dublán y Lozano hijos, 34 vols.

Escudero, José Agustín, Memorias del diputado por el Estado de Chihuahua, con documentos justificativos, que pueden servir para la historia del Congreso Constituyente mexicano del año de 1847, 1848, México, Tipografía de R. Rafael.

Exposición dirigida al Supremo Gobierno por los Comisionados que formaron el Tratado de Paz con los Estados Unidos, 1848, Querétaro, Imp. de J.M. de Lara.

Malo, José Ramón, Diario de Sucesos Notables (1832-1853), 1948, México, Patria.

Poder Ejecutivo, Colección de los documentos más importantes relativos a la instalación y reconocimiento del Gobierno Provisional del Excmo. Sr. 


\section{REYNALDO SORDO}

presidente de la Suprema Corte de Justicia D. Manuel de la Peña y Peña, 1847, México, Ignacio Cumplido, 80 p.

Prieto, Guillermo, Memorias de mis tiempos, 1985, México, Porrúa, Sepan Cuantos $n^{\circ} 481$.

Sordo Cedeño, Reynaldo, "El Congreso y la guerra con Estados Unidos de América, 1846-1848", en Josefina Vázquez (coord.), México al tiempo de su guerra con Estados Unidos (1846-1848), 1997, México, FCE-El Colegio de México-SRE, p. 47-103.

Sordo Cedeño, Reynaldo y Josefina Vázquez, En defensa de la Patria, 1847-1997, 1997, México, Comisión organizadora de los Homenajes del CL Aniversario de los Niños Héroes-Secretaría de Gobernación-Archivo General de la Nación.

Sordo Cedeño, Reynaldo, "Paz o Guerra. Junta de Gobernadores en Querétaro, noviembre de 1847", Ponencia dictada en el Archivo General de la Nación el 13 de noviembre de 1997 (en prensa).

Suárez Argüello, Ana Rosa, De Maine a México. La misión diplomática de Nathan Clifford (1848-1849), 1994, México, SRE-Instituto Mora.

Vázquez, Josefina Z. (coord.), Planes en la Nación Mexicana, 1987, México, Senado de la República-El Colegio de México, Libro cuatro. 